\title{
SÍNTESE E CARACTERIZAÇÃO DE CATALISADORES SOL- GEL DESTINADOS À REFORMA A VAPOR DE METANOL
}

\author{
A. C. FORNARI ${ }^{1}$, C. H. M. KUWABARA ${ }^{1}$, T. C. FERRARI ${ }^{1}$, R. MENECHINI NETO ${ }^{1}$, R. M. \\ M. JORGE ${ }^{2}$, O. A. A. dos SANTOS ${ }^{1}$, G. G. LENZI ${ }^{3}$ e L. M. M. JORGE ${ }^{1}$ \\ ${ }^{1}$ Universidade Estadual de Maringá, Departamento de Engenharia Química \\ ${ }^{2}$ Universidade Federal do Paraná, Departamento de Engenharia Química \\ ${ }^{3}$ Universidade Tecnológica Federal do Paraná, Departamento de Engenharia Química \\ E-mail para contato: ariellecfornari@hotmail.com / lmmj@deq.uem.br
}

\begin{abstract}
RESUMO - A proposta do presente trabalho foi sintetizar seis catalisadores $\mathrm{CuO} / \mathrm{ZnO} / \mathrm{Al}_{2} \mathrm{O}_{3}$, em diferentes concentrações, pelo método sol-gel, para posterior aplicação na reação de reforma a vapor de metanol. Foram realizadas as seguintes análises para a caracterização das amostras: TGA, Área BET, volume de poros e DRX. Como resultado obteve-se catalisadores com alta área superficial, sendo que a área específica e o volume de poros dos materiais diminuíram com o aumento da concentração de $\mathrm{Cu}$ e $\mathrm{Zn}$, devido ao aumento da coalescência dos cristalitos. As análises de DRX indicaram um aumento da cristalinidade com o aumento da concentração de $\mathrm{Cu}$ e $\mathrm{Zn}$ e diminuição da concentração de $\mathrm{Al}_{2} \mathrm{O}_{3}$. Além disso, observou-se a presença de diferentes fases metálicas nas amostras, resultantes do método de preparo e das modificações ocorridas na calcinação.
\end{abstract}

\section{INTRODUÇÃO}

O alto custo dos combustíveis fósseis em adição a considerações ambientais têm feito células a combustível uma alternativa interessante aos motores de combustão interna que operam com derivados de petróleo. Entretanto, o armazenamento do hidrogênio combustível como líquido ou gás pressurizado em um veículo motor é inviável. Com isso, é preferível possuir uma fonte de hidrogênio na forma líquida, que o produza quando este é requerido (Jones, 2008).

A reforma a vapor do metanol tem sido muito investigada nos últimos anos para a produção de hidrogênio com baixo teor de monóxido de carbono para células a combustível (Vadlamudi e Palanki, 2011), pois o metanol possui uma alta proporção hidrogênio/carbono, além de poder ser reformado a temperaturas relativamente baixas (Jones, 2008). Neste sentido, diversos pesquisadores têm estudado a reforma a vapor do metanol, utilizando vários tipos de catalisadores (Israni e Harold, 2011; Jiang et al., 1993; Kawamura et al., 2008).

$\mathrm{O}$ catalisador mais comum para a reforma do metanol é o $\mathrm{CuO} / \mathrm{ZnO} / \mathrm{Al}_{2} \mathrm{O}_{3}$. Para esta reação, verificou-se que o cobre possui atividade catalítica (Jiang et al., 1993). Já o óxido de zinco é adicionado para melhorar a dispersão do $\mathrm{Cu}$ e reduzir a micro-tensão na superfície do 


\section{9 a 22 de outubro de 2014 \\ Florianópolis/SC}

catalisador, e a alumina é utilizada como suporte para fornecer uma alta área para a reação, aumentando sua velocidade. Vários trabalhos relatam a utilização deste catalisador e estudam o mecanismo e a cinética da reação (Jones et al., 2008; Purnama et al., 2004).

Um fator muito relevante para as reações catalíticas é o método de preparação de catalisadores suportados, pois influencia fortemente seu estado, forma, dispersão e distribuição final, afetando diretamente a atividade catalítica. Um dos métodos de preparo de catalisadores que está sendo recentemente destacado por vários autores é o método da mistura química ou solgel. O método sol-gel representa uma alternativa vantajosa para a síntese de catalisadores, pois conduz a materiais mais homogêneos, com alta porosidade e dispersão da fase ativa (Gonçalves et al., 2006; Colpini et al., 2013). Entretanto, não há referência sobre sua utilização na reforma a vapor do metanol.

Com o exposto acima, e levando em conta a importância das caracterizações estruturais e texturais dos catalisadores para explicar, prever e justificar algumas de suas principais propriedades, tais como atividade, seletividade e estabilidade, este trabalho teve como objetivos sintetizar e caracterizar catalisadores com diferentes cargas metálicas de cobre e zinco pelo método sol-gel e compará-los com o catalisador comercial que é aplicado na reforma do metanol.

\section{PROCEDIMENTO EXPERIMENTAL}

\subsection{Síntese dos Catalisadores}

Os catalisadores foram sintetizados seguindo a metodologia proposta por Pearson et al. (1983) e modificada por Santos (1999). Foram preparados seis catalisadores $\mathrm{CuO}-\mathrm{ZnO}_{-} \mathrm{Al}_{2} \mathrm{O}_{3}$ pelo método sol-gel, com diferentes composições de cobre, zinco e alumina, mantendo constante a proporção mássica cobre/zinco do catalisador comercial utilizado para a reforma a vapor do metanol (HiFUEL R120, Alfa Aesar ${ }^{\circledR}, \mathrm{Cu} / \mathrm{Zn}: 1,66$ ).

Em um béquer com agitação magnética adicionou-se $10 \mathrm{~mL}$ de álcool etílico (Nuclear, pureza > 99,5\%), ao qual foram adicionados nitrato de cobre trihidratado $\left(\mathrm{Cu}\left(\mathrm{NO}_{3}\right)_{2} .3 \mathrm{H}_{2} \mathrm{O}\right.$, Sigma-Aldrich, > 99\%) e nitrato de zinco hexahidratado $\left(\mathrm{Zn}\left(\mathrm{NO}_{3}\right)_{2} \cdot 6 \mathrm{H}_{2} \mathrm{O}\right.$, Sigma-Aldrich, > 99\%). A seguir adicionou-se álcool etílico suficiente para dissolver completamente os sais. Esta solução foi transferida para um balão de três bocas imerso em um banho de glicerina, ao qual foram acoplados um agitador mecânico, um condensador (através do qual passava água corrente à temperatura ambiente) e um funil de adição. $\mathrm{O}$ banho de glicerina estava sobre uma chapa de aquecimento e sua temperatura era controlada por meio de um termômetro digital.

A solução transferida foi agitada por 15 min à temperatura ambiente. Ao ligar-se o aquecimento adicionou-se hexilenoglicol (Sigma-Aldrich, 99\%) lentamente com o funil de adição. $\mathrm{O}$ hexilenoglicol serviu como solvente para o precursor da alumina, e foi adicionado na proporção mássica hexilenoglicol/isopropóxido de alumínio = 1,16. Quando o banho de glicerina atingiu $95{ }^{\circ} \mathrm{C}$, deixou-se a mistura agitando por $30 \mathrm{~min}$. A seguir adicionou-se, com o auxílio de um funil, isopropóxido de alumínio (Sigma-Aldrich, pureza > 98\%). Deixou-se a mistura sob 


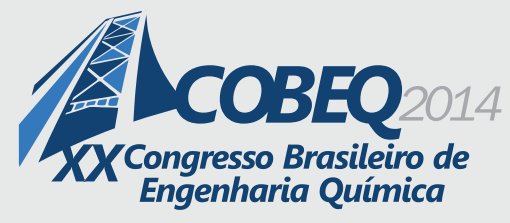

19 a 22 de outubro de 2014
Florianópolis/SC

agitação a $95^{\circ} \mathrm{C}$ por $4 \mathrm{~h}$. Posteriormente foi feita a etapa da hidrólise, adicionando-se lentamente uma solução 1:1 (v/v) de etanol e água (com o funil de adição), observando-se uma proporção molar água/isopropóxido de alumínio de 4,5. A mistura ficou sob agitação por mais $3 \mathrm{~h}$.

Depois de resfriado, o balão foi deixado em repouso, para envelhecimento, fechado e em temperatura ambiente, por $85 \mathrm{~h}$. Nesta etapa ocorre a organização e ordenamento das partículas e cristalitos da fase ativa no catalisador, devido ao contato com a solução-mãe. Após este período fez-se uma rota-evaporação a vácuo por 90 min a $70{ }^{\circ} \mathrm{C}$, para remover o álcool e um pouco da água residual. $\mathrm{O}$ catalisador (gel) foi seco numa estufa com circulação de ar, a $70{ }^{\circ} \mathrm{C}$ por $48 \mathrm{~h}$, deixado no dessecador por $48 \mathrm{~h}$ e seco numa linha de vácuo por $16 \mathrm{~h}\left(6 \mathrm{~h}\right.$ a $70{ }^{\circ} \mathrm{C}, 6 \mathrm{~h}$ a $100{ }^{\circ} \mathrm{C} \mathrm{e}$ $4 \mathrm{~h}$ a $150{ }^{\circ} \mathrm{C}$ ), para a remoção de nitratos e do hexilenoglicol. Por fim, o pó obtido foi calcinado a $400{ }^{\circ} \mathrm{C}$ por $5 \mathrm{~h}$ (com uma rampa de aquecimento de $1,6^{\circ} \mathrm{C} / \mathrm{min}$ ) para a obtenção do precursor final, e pastilhado com uma pressão de 3 ton.

Na Tabela 1 são listados os seis catalisadores sol-gel preparados e o catalisador comercial HiFUEL R120 e suas composições. As composições dos metais nos catalisadores foram obtidas através de espectroscopia de absorção atômica no Atomic Absorption Spectrometer SpectrAA 50B da VARIAN, após a abertura das amostras. No caso do catalisador comercial, a composição esperada é a fornecida na ficha técnica do produto e a composição real é a que consta na ficha de análise do lote utilizado em particular (lote L04Y006), que diferiram entre si. As porcentagens e frações são expressas na forma mássica.

Tabela 1 - Composições dos catalisadores

\begin{tabular}{c|c|c|c|c|c|c|c|c}
\hline Catalisador & $\mathbf{A 1}$ & $\mathbf{A 2}$ & $\mathbf{A 3}$ & $\mathbf{A 4}$ & $\mathbf{A 5}$ & $\mathbf{A 6}$ & $\begin{array}{c}\text { HiFUEL R120 }^{\circledR} \\
\text { esperado }\end{array}$ & $\begin{array}{c}\text { HiFUEL R120 }^{\circledR} \\
\text { Real }\end{array}$ \\
\hline$\% \mathrm{Cu}$ & 8,9 & 17,3 & 23,4 & 34,4 & 40,6 & 48,4 & 39,9 & 51,2 \\
\hline$\% \mathrm{Zn}$ & 4,8 & 9,8 & 15,0 & 20,0 & 23,1 & 28,8 & 24,1 & 19,6 \\
\hline$\% \mathrm{Al}$ & 34,8 & 27,7 & 21,5 & 16,5 & 9,0 & 1,7 & 10,6 & 5,1 \\
\hline Razão Cu/Zn & 1,85 & 1,77 & 1,57 & 1,72 & 1,76 & 1,68 & 1,66 & 2,61 \\
\hline
\end{tabular}

\subsection{Caracterizações dos Catalisadores}

As caracterizações foram realizadas com partículas de diâmetro 0,6 $\mathrm{mm}<\mathrm{d}<0,85 \mathrm{~mm}$ (as pastilhas de catalisador foram trituradas e peneiradas nesta granulometria), exceto a difração de raios $X(D R X)$, que foi feita com partículas de diâmetro menor que 0,6 mm.

TGA-DSC: A Análise Termogravimétrica (TGA) se baseia na perda de massa da amostra quando submetida a um aumento gradual e constante de temperatura. A Calorimetria Exploratória Diferencial (DSC) é uma medida de fluxo de calor, que permite identificar mudanças de fase (mudanças estruturais, reações e transições sólido-sólido, cristalização, fusão, polimerização e reações catalíticas) que ocorrem na amostra com a variação de temperatura (Haines, 1992). O equipamento utilizado no TGA-DSC foi o analisador térmico simultâneo NETZSCH STA 449 F3 Jupiter $^{\circledR}$. O intuito da realização destas análises nas amostras A1 e A2 não calcinadas foi verificar a melhor temperatura de calcinação. 
Área BET, volume de poros e diâmetro médio de poros: Estas análises foram realizadas em equipamento NOVA 1000 series da QUANTACHROME, e analisadas no programa NovaWin versão 10.01, através das isotermas de adsorção e dessorção de nitrogênio a $77 \mathrm{~K}$, para todos os catalisadores. Adicionalmente, foram feitas análises dos catalisadores não pastilhados. $\mathrm{Na}$ determinação da área específica as amostras foram previamente tratadas a $300{ }^{\circ} \mathrm{C}$ por $5 \mathrm{~h}$ para eliminar a água adsorvida e possíveis condensados existentes nos poros dos sólidos.

Difração de raios X (DRX): Os difratogramas de raios $X$ das amostras calcinadas foram obtidos em um Difratômetro D8 Advance da BRUKER, utilizando radiação $\mathrm{CuK} \alpha(\mathrm{V}=40 \mathrm{kV}$, I $=35 \mathrm{~mA}$ ), e comparados com o conjunto de dados de difração do Joint Committee of Powders Diffraction Standards (JCPDS) através do programa X'pert Highscore Plus.

\section{RESULTADOS E DISCUSSÕES}

\subsection{TGA-DSC}

Os resultados de TGA-DSC dos catalisadores A1 e A2 não calcinados são apresentados nas Figuras 1 e 2, respectivamente.

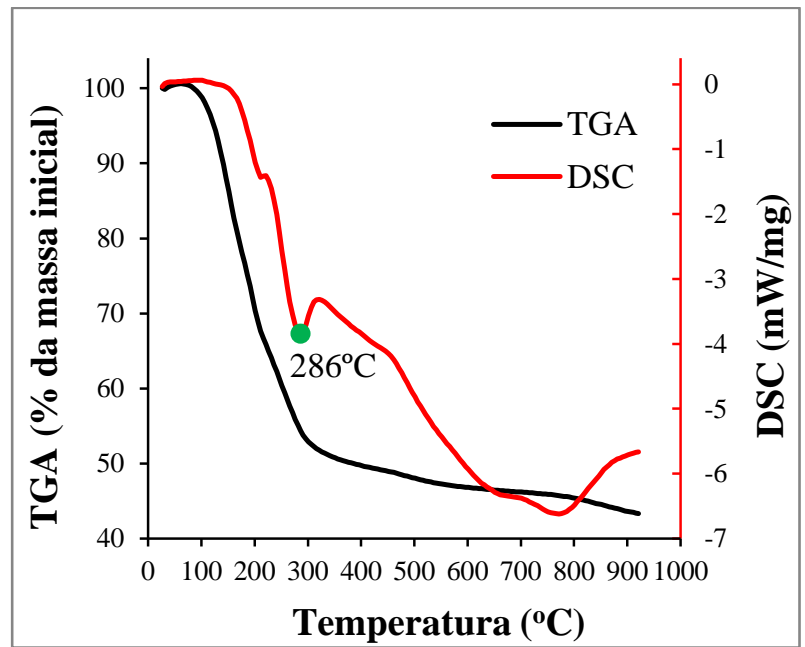

Figura 1 - TGA-DSC do catalisador A1. A massa utilizada na análise foi de $11,972 \mathrm{mg}$.

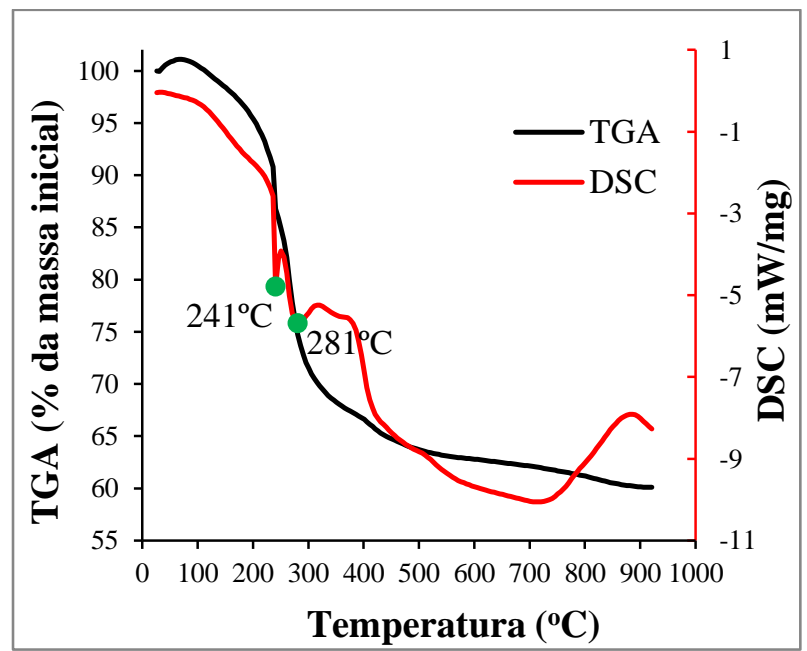

Figura 2 - TGA-DSC do catalisador A2. A massa utilizada na análise foi de $9,987 \mathrm{mg}$.

Conforme pode ser observado nas Figuras 1 e 2, ocorreu uma mudança de fase a aproximadamente $286^{\circ} \mathrm{C}$ para o catalisador A1 e duas mudanças de fase (a $241{ }^{\circ} \mathrm{C}$ e $281{ }^{\circ} \mathrm{C}$ ), para o catalisador A2. Essas mudanças são indicadas pela variação na inclinação da curva de DSC, formando picos mínimos. Além disso, ocorreu outra transição acima de $700{ }^{\circ} \mathrm{C}$ para ambos os catalisadores. Entretanto, como as temperaturas reacionais não passam de $350{ }^{\circ} \mathrm{C}$, esta transição a temperaturas mais elevadas não irá ocorrer. Pelas curvas de TGA pode ser observado também que a variação mássica mais drástica ocorreu na região que vai da temperatura ambiente até $400{ }^{\circ} \mathrm{C}$, variando pouco a partir daí. 


\section{9 a 22 de outubro de 2014 \\ Florianópolis/SC}

Com os resultados obtidos pelas análises de TGA e DSC para estes dois catalisadores, decidiu-se calcinar todos os catalisadores a $400{ }^{\circ} \mathrm{C}$, podendo-se dizer que até esta temperatura já ocorreram as transições necessárias e que a maior parte dos precursores já foi decomposta. Para a caracterização das estruturas presentes no catalisador final (obtido após a calcinação), foi feita a difração de raios $\mathrm{X}$, discutida no item 3.3.

\section{2. Área BET, Volume Total de Poros e Diâmetro Médio de Poros}

Os resultados das caracterizações texturais dos catalisadores (pastilhados $(\mathrm{P})$ e não pastilhados (NP)) são mostrados na Tabela 2.

Tabela 2 - Análise textural dos catalisadores

\begin{tabular}{|c|c|c|c|c|c|c|}
\hline \multirow[t]{2}{*}{ Catalisador } & \multicolumn{2}{|c|}{ Área BET $\left(\mathrm{m}^{2} / \mathrm{g}\right)$} & \multicolumn{2}{|c|}{$\begin{array}{l}\text { Volume total de poros } \\
\qquad\left(\mathrm{cm}^{3} / \mathrm{g}\right)\end{array}$} & \multicolumn{2}{|c|}{$\begin{array}{c}\text { Diâmetro médio de } \\
\operatorname{poros}(\AA)\end{array}$} \\
\hline & $\mathrm{P}$ & NP & $\mathrm{P}$ & NP & $\mathrm{P}$ & NP \\
\hline A1 & 286,6 & 357,7 & 0,373 & 0,803 & 54 & 90 \\
\hline A2 & 199,3 & 209,8 & 0,240 & 0,556 & 48 & 106 \\
\hline A3 & 124,7 & 155,1 & 0,123 & 0,785 & 39 & 202 \\
\hline A4 & 32,6 & 35,9 & 0,033 & 0,131 & 40 & 146 \\
\hline A5 & 65,8 & 94,0 & 0,070 & 0,403 & 42 & 171 \\
\hline $\mathrm{A} 6$ & 12,9 & 12,5 & 0,014 & 0,040 & 44 & 128 \\
\hline HiFUEL R120 & \multicolumn{2}{|c|}{95,4} & \multicolumn{2}{|c|}{0,156} & \multicolumn{2}{|c|}{65} \\
\hline
\end{tabular}

Pode-se observar na Tabela 2 que o pastilhamento dos catalisadores após sua calcinação reduziu a área superficial, o volume e o diâmetro dos poros. Isso se deve à compressão exercida sobre estes, que faz os átomos e moléculas se reorganizarem mais próximos uns dos outros. Comparando-se tanto a área quanto o volume total de poros, pode-se dizer que, à exceção do catalisador A4, todos apresentaram um comportamento decrescente da área e do volume de poros com o aumento da porcentagem de cobre e zinco e diminuição de alumínio. Com a redução da alumina (que atua como um suporte para a fase ativa), os cristalitos de cobre e zinco tendem a se aglomerar, resultando em uma menor área para o catalisador (a finalidade do suporte é justamente aumentar a área superficial e melhorar a dispersão da fase ativa).

Conforme pode ser observado na Tabela 2, os catalisadores preparados pelo método sol-gel apresentaram elevadas áreas superficiais, pois este método favorece a interação entre a fase metálica e a fase óxida em sistemas metal-óxido por promover o contato íntimo entre estas duas fases, além de permitir modificações nas propriedades estruturais do catalisador (Santos, 1999; Xia et al., 2012; Colpini et al., 2013). Entretanto, como a área é extremamente dependente da porcentagem metálica, qualquer variação nesta produz variâncias significativas na textura do catalisador, fato comprovado pelas medidas acima. Portanto, como os catalisadores preparados pelo método sol-gel não apresentaram composição similar à composição real do catalisador industrial utilizado (informada pela empresa fabricante), comparações acerca da área superficial entre estes não podem ser feitas por enquanto. 


\subsection{DRX}

Os difratogramas dos catalisadores preparados são apresentados nas Figuras 3 e 4.

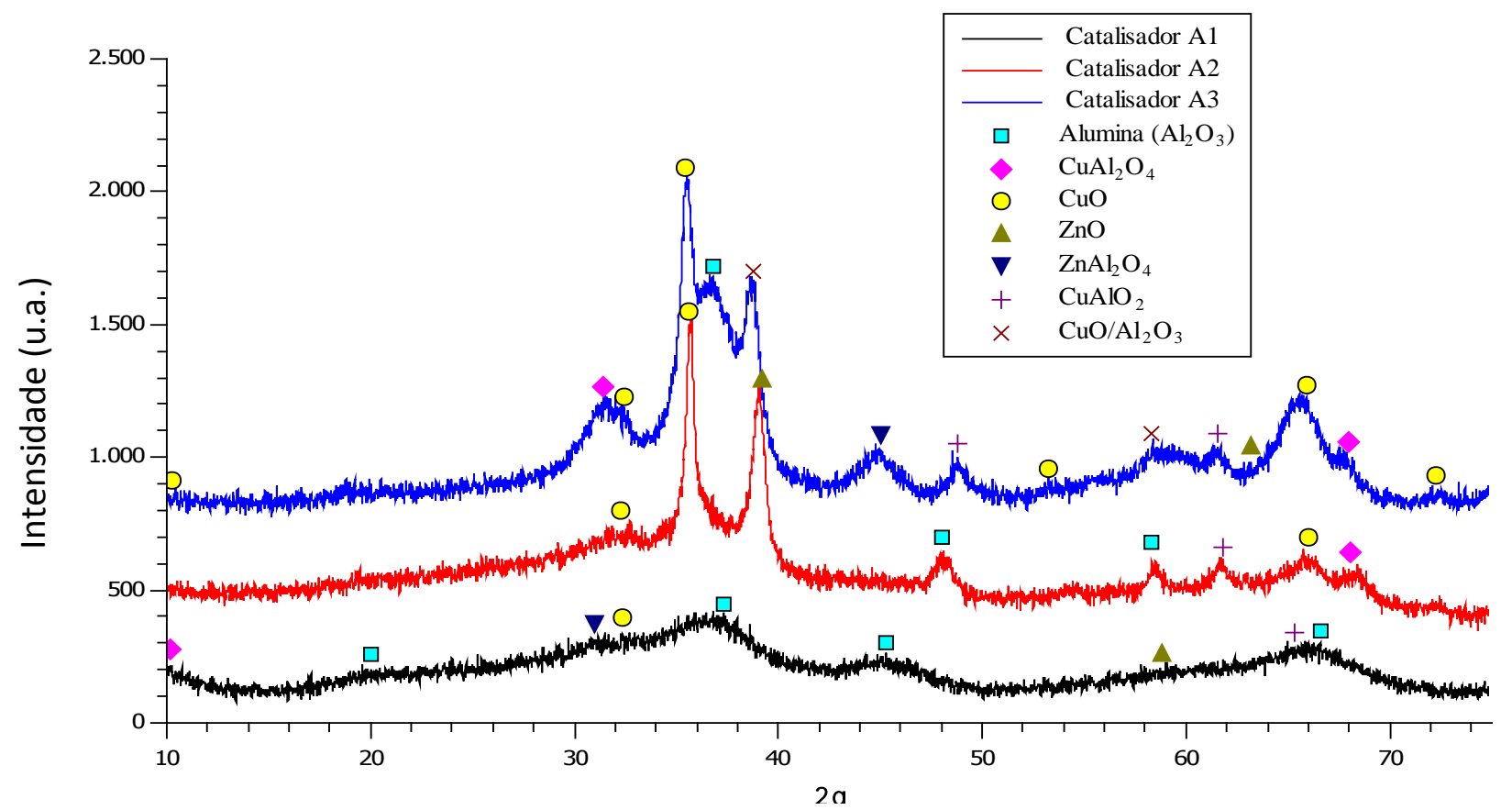

Figura 3 - Difratogramas de raios $\mathrm{X}$ dos catalisadores A1, A2 e A3.

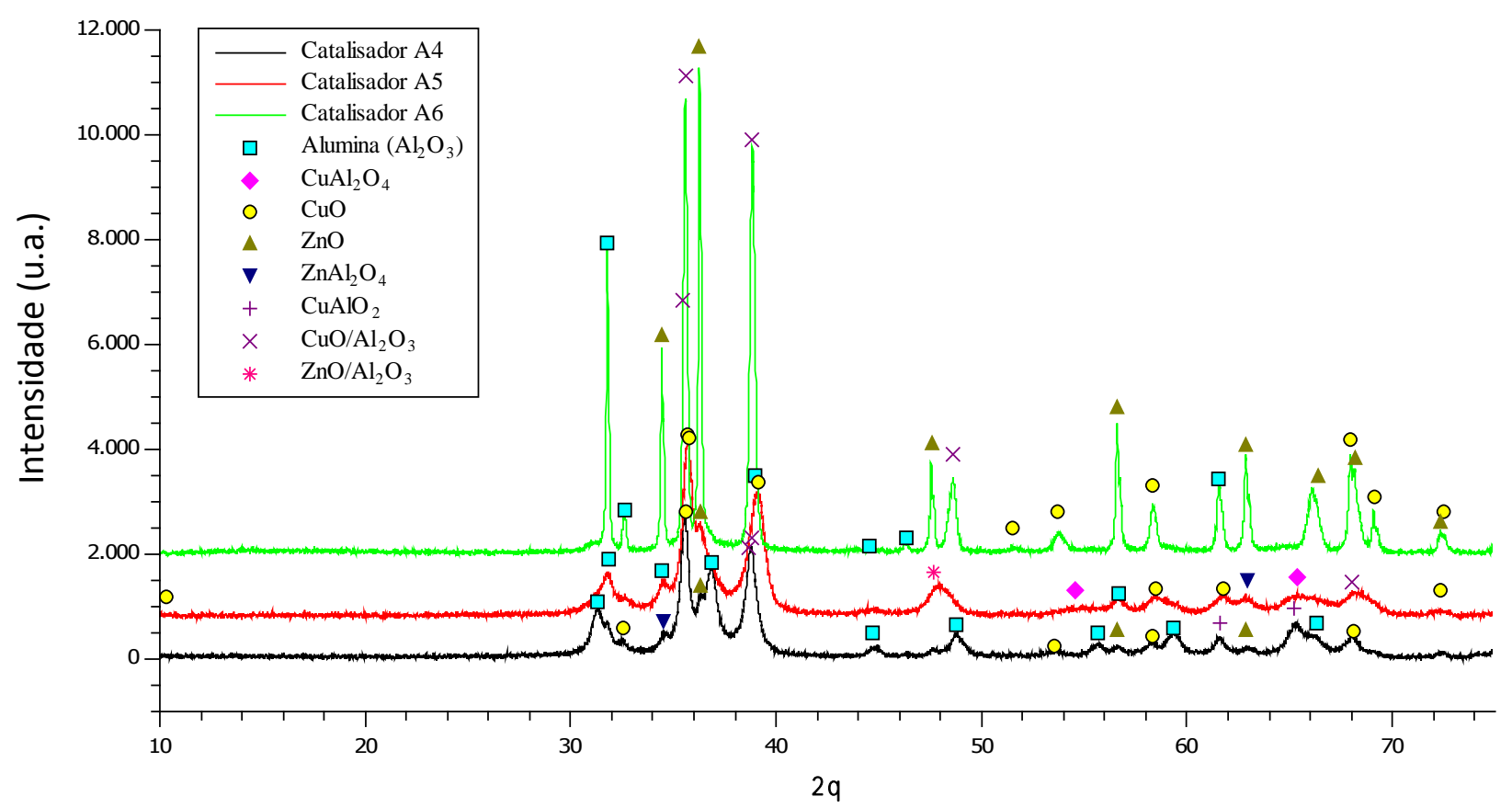

Figura 4 - Difratogramas de raios X dos catalisadores A4, A5 e A6. 
Como pode ser observado nas Figuras 3 e 4, a cristalinidade do material foi aumentando conforme aumentou-se a quantidade de cobre e zinco nos catalisadores (i.e. diminuindo-se a de alumina). O catalisador A1 se mostrou amorfo, devido à maior porcentagem de alumina. Entretanto, a não identificação de picos para este também pode ser sinal de cristalitos muito pequenos, não detectados pelo DRX. O catalisador A6 se mostrou o mais cristalino, sendo as principais fases presentes a tenorita $(\mathrm{CuO})$ monoclínica e a zincita $(\mathrm{ZnO})$ hexagonal.

Quando a proporção de cobre e zinco aumentou drasticamente, os picos dos difratogramas correspondentes aumentaram. Além disso, foi verificada a presença não só das fases esperadas $\left(\mathrm{Al}_{2} \mathrm{O}_{3}, \mathrm{CuO}\right.$ (tenorita) e $\mathrm{ZnO}$ (zincita)), mas também de fases metálicas compostas $\left(\mathrm{ZnAl}_{2} \mathrm{O}_{4}\right.$, $\mathrm{CuAl}_{2} \mathrm{O}_{4}$ e $\mathrm{CuAlO}_{2}$ ), indicando uma diferente interação suporte-fase ativa.

\section{CONCLUSÕES}

As análises realizadas neste trabalho indicaram que os catalisadores preparados apresentaram características distintas dependendo da concentração de $\mathrm{Cu}, \mathrm{Zn}$ e $\mathrm{Al}$. As áreas superficiais obtidas variaram de 12 a $360 \mathrm{~m}^{2} / \mathrm{g}$ somente variando-se a concentração destes metais. Áreas e volumes de poros maiores foram observados para os catalisadores com menor proporção da fase ativa e maior proporção do suporte, o que indica claramente a função do suporte num catalisador heterogêneo: aumentar a área superficial para melhorar a dispersão da fase ativa. Além disso, foram verificadas diferentes cristalinidades para os materiais, que aumentaram conforme o aumento das cargas metálicas de $\mathrm{Cu}$ e $\mathrm{Zn}$ (que apresentam maior cristalinidade que a alumina).

Para uma reação catalítica heterogênea, uma boa combinação para o catalisador são altas área específica, dispersão da fase ativa e cristalinidade. Conforme foi verificado, a cristalinidade dos materiais aumentou com a diminuição da área superficial. Portanto, nada se pode afirmar ainda sobre a atividade e seletividade dos catalisadores preparados. Entretanto, as análises realizadas em conjunto com outras caracterizações tais como dessorção à temperatura programada (TPD), redução à temperatura programada (TPR), microscopia eletrônica de transmissão (MET) e dispersão metálica, podem justificar um comportamento catalítico.

Os próximos passos deste trabalho envolvem a realização de outras caracterizações dos catalisadores (TPR, TPD, MEV, MET, quimissorção) e dos testes catalíticos em um reator diferencial de leito fixo. Com isso, as características apresentadas poderão ser relacionadas à atividade dos catalisadores.

\section{AGRADECIMENTOS}

Os autores agradecem à Coordenação de Aperfeiçoamento de Pessoal de Nível Superior CAPES - Brasil pelo apoio financeiro. 


\section{REFERÊNCIAS BIBLIOGRÁFICAS}

COLPINI, L. M. S.; LENZI, G. G.; MARTINS, L.; GONZÁLEZ, E. A. U.; SANTOS, O. A. A. e COSTA, C. M. M. Selective catalytic reduction of $\mathrm{NO}$ with propane on $\mathrm{V}_{2} \mathrm{O}_{5} / \mathrm{SiO}_{2}$, $\mathrm{V}_{2} \mathrm{O}_{5} / \mathrm{TiO}_{2}$, and $\mathrm{V}_{2} \mathrm{O}_{5} / \mathrm{Al}_{2} \mathrm{O}_{3}$ catalysts obtained through the sol-gel method. Acta Sci. Tech., v. 15, p. 139-145, 2013.

GONÇALVES, G.; LENZI, M. K.; SANTOS, O. A. A. e JORGE, L. M. M. Preparation and characterization of nickel based catalysts on silica, alumina and titania obtained by the solgel method. Jour. of Non-Cryst. Solids, v. 352, p. 3697-3704, 2006.

HAINES, P. J. Principles of Thermal Analysis and Calorimetry. Cambridge, UK: Lynx Edicions, 1992.

ISRANI, S. H. e HAROLD, M. P. Methanol steam reforming in single fiber packed bed Pd-Ag membrane reactor: experiments and modeling. J. of Memb. Sci., v. 369, p. 375-387, 2011.

JIANG, C. J.; TRIMM, D. L.; WAINWRIGHT, M. S. e CANT, N. W. Kinetic study of steam reforming of methanol over cooper-based catalysts. App. Cat. A: Gen., v. 93, p. 245-255, 1993.

JONES, S. D.; NEAL, L. M. e HAGELIN-WEAVER, H. E. Steam reforming of methanol using $\mathrm{Cu}-\mathrm{ZnO}$ catalysts supported on nanoparticle alumina. App. Cat. B: Env., v. 84, p. 631-642, 2008.

KAWAMURA, Y.; ISHIDA, T.; TEZUKA, W. e IGARASHI, A. Hydrogen production by oxidative methanol reforming with various oxidants over $\mathrm{Cu}$-based catalysts. Chem. Eng. Sci., v. 63, p. 5042-5047, 2008.

PEARSON, I. M.; RYU, H.; WONG, W. C. e NOBE, K. Chemical Mixed' Catalysts. Ind. Eng. Chem. Prod. Res. Dev., v. 22, p. 381-382, 1983.

PURNAMA, H.; RESSLER, T.; JENTOFT, R. E.; SOERIJANTO, H.; SCHLÖGL, R. e SCHOMÄCKER, R. CO formation/selectivity for steam reforming of methanol with a commercial CuO/ZnO/Al ${ }_{2} \mathrm{O}_{3}$ catalyst. App. Cat. A: Gen., v. 259, p. 83-94, 2004.

SANTOS, O. A. A. Hidrogenação Seletiva do Ácido Oléico em Catalisadores de Rutênio. Tese de Doutorado, Universidade Estadual de Campinas, 1999.

VADLAMUDI, V. K. e PALANKI, S. Modeling and analysis of miniaturized methanol reformer for fuel cell powered mobile applications. Intern. J. of Hyd. Ener., v. 36, p. 3364-3370, 2011.

XIA, W. S.; HOU, Y. H.; CHANG, G.; WENG, W. Z.; HAN, G. B. e WAN, H. L. Partial oxidation of methane into syngas $\left(\mathrm{H}_{2}+\mathrm{CO}\right)$ over effective high-dispersed $\mathrm{Ni} / \mathrm{SiO}_{2}$ catalysts synthesized by a sol-gel method. Intern. J. of Hyd. Ener., v. 37, p. 8343-8353, 2012. 